\title{
SURFACE TOPOGRAPHY AND CHEMICAL CHARACTERISTICS OF ROTARY NI TI FILES OF DIFFERENT MANUFACTURING TECHNIQUES AFTER MULTIPLE USE
}

\author{
AbdAllah D.M*, Elddamony E.M ${ }^{* *}$ and Abdelgawad R.A*
}

\begin{abstract}
Background: This study designed to evaluate and compare surface physical and chemical characteristics of recently introduced rotary NiTi files Neolix (Neolix, Châtres-la-Forêt, France), One Curve (Micro mega, France) and AF ${ }^{\mathrm{TM}}$ Blue S ONE File System (Fanta, USA) before and after $1^{\text {st }}$ and $3^{\text {rd }}$ use.
\end{abstract}

Materials and Methods: In this study thirty brand-new endodontic files having tip size 25/0.6 of the following systems were used: Neolix (Neolix, Châtres-la-Forêt, France), One Curve (Micro mega, France) and AF ${ }^{\mathrm{TM}}$ Blue S ONE One-File System (Fanta, USA). These files were equally divided into three groups $(\mathrm{n}=10)$. Ninety simulated curved canals (Endo Training Block-L; Dentsply Maillefer, Ballaigues, Switzerland) with curvature of $45^{\circ} \pm 10^{\circ}$, with 0.02 taper, $0.15 \mathrm{~mm}$ apical diameter, and $16 \mathrm{~mm}$ length were used. File`s surfaces examined by Environmental Scanning Electron Microscope ESEM (FEI Quanta 250 FEG, Berlin, Germany) at 500X magnification before use. Cutting blade (active part) images been processed and their micrographs were analyzed at the tip, 2 and $4 \mathrm{~mm}$ short of its cutting tip. The Nickel (Ni) and Titanium (Ti) average contents (wt $\%)$ on the instrument's surface were also analyzed before their use, using an Energy Dispersive Spectrometer Device (EDAX - AMETEK, Inc., Mahwah, NJ, USA). All instruments prepared using electric motor (Motor X-Smart Plus, Dentsply/Maillefer), following manufacturer`s instructions for each system. Each used file prepared three simulated canals, after each canal instrumentation, each file was removed for cleaning its flutes gently with sterile gauze, and for canal irrigation using with $2 \mathrm{~mL} / 2.5 \% \mathrm{NaOCl}$ irrigating solution. After the first and third instrumentation performed; files were cleaned, dried, stored and sent to SEM equipment for post-instrumentation files surface's topography analysis and chemical composition of the NiTi content (wt \%) according to the previously described pre-instrumentation analysis protocol. SEM micrographs recorded on a CDROM and projected for three blinded examiners'. They were given a spreadsheet including the instrument data (number, the location to be evaluated; tip, $0-2 \mathrm{~mm}$ or $2-4 \mathrm{~mm}$ from the tip) and the side of the instrument (detail facing up or down), and the criteria of defects and deformation assessment namely (irregular edges, grooves, micro-cavities and burrs).Data were recorded and statistically analyzed.

\footnotetext{
* Lecturer in Endodntic Department, Faculty of Dentistry, Suez Canal University

** Lecturer in Dental Materials Department, Faculty of Dentistry, Suez Canal University
} 
Results: Analysis of surface defects (SEM) showed that; all file systems have preinstrumentation surface defects which increased after use. Neolix file had highest significant difference in all detected surface defects with One Curve file, with $\mathrm{AF}^{\mathrm{TM}}$ Blue S ONE file in burs and micro-cavities at file`s Tip and $0-2 \mathrm{~mm}$, in all examination intervals $(\mathrm{p}<0.05)$. One Curve file showed the least surface defects with significant difference with $\mathrm{AF}^{\mathrm{TM}}$ Blue $\mathrm{S}$ ONE file in edges mean values at file's Tip at all examination intervals. EDS chemical analysis of $\mathrm{Ni}$ and Ti\% revealed; decrease in $\mathrm{Ni}$, Ti weight $\%$ after first and third uses. Decrease in $\mathrm{Ni} \%$ was more than Ti\%.

Conclusion: surface defects of the studied instruments were recorded before use, continuous use promoted their increase. Chemical change results revealed significant changes in $\mathrm{Ni}$ and $\mathrm{Ti}$ content on instruments surface after reuse led to that may affect their performance.

KEY WORDS: surface topography, chemical characteristics, SEM, EDAX, Neolix, One Curve and $\mathrm{AF}^{\mathrm{TM}}$ Blue $\mathrm{S}$ ONE

\section{INTRODUCTION}

The innovative Nickel-titanium alloy (NiTi) was developed in 1960's owns amazing mechanical properties "superelasticity and shape memory", their flexibility can be inferred to its lower modulus of elasticity compared to stainless steel, while the ductility of the alloy is responsible for its superior fracture resistance ${ }^{(1)}$. In 1988 Walia et al. put in the first manual NiTi files in endodontic field ${ }^{(1)}$. The increased popularity of NiTi rotary files have manifested in its safe, efficient, and well adaptation to shape root canals with severe curvature ${ }^{(2,3)}$. As the popularity of traditional NiTi files increased, manufacturers have focused their efforts on the improvement of NiTi performance to make them efficiently used, resist deformation and fracture (3), to overcome their unexpected failures happened regardless of visibly permanent plastic deformation free surface ${ }^{(4)}$. Various approaches of files cross sectional design modification proved have ability to alter the mechanical features of rotary files ${ }^{(5)}$. One the other hand; manufacturing of these NiTi rotary files requires a special procedure, and could result in an increased surface defects concentration including; debris, pits, metal strips and blunt cutting edges ${ }^{(6)}$. Therefore, different manufacturing strategies including; heat treatment processes and different thermo-mechanical treatments, have been continuously intended for $\mathrm{Ni}-\mathrm{Ti}$ instruments mechanical properties improvement, as; fatigue fracture resistance, flexibility, and risk of fracture ${ }^{(7,8)}$. New single-file systems have innovated in endodontic practice utilizing either rotation or reciprocation motions gained huge popularity as they include: only a single file that require a minimum or no glide path to complete instrumentation of root canals, the recommendation for use the file only once has gained advantage of minimizing instrument fatigue and eliminating cross contamination between patients, and reducing the working time ${ }^{(9,10)}$. Newly introduced full rotary motion single-file systems investigated in this study include; Neolix (Neolix, Châtres-la-Forêt, France) that made up of special alloy with a non-homogeneous rectangular cross section that enhances the file flexibility. According to the manufacturer it offers many advantages such as sharp cutting edges, Gothic-like tip design and built-in abrasive properties ${ }^{(11)}$. It is manufacturing utilizing a recently introduced wire-cut electrical discharge machining (WEDM) mechanism, which creates a rough surface, adding abrasive properties that increase root canal preparation speed. These files undergo suitable heat treatment which earn the instrument higher flexibility and shape memory ${ }^{(12)}$. Another recently introduced single rotary file is the One Curve (Micro mega, France) file that is manufactured from heat-treated NickelTitanium alloy (C. Wire). The manufacturer claims, this file has a unique manufacturing technique that implemented by MICRO-MEGA for developing a controlled memory NiTi files that can be 
pre-bend for easier instrumentation of the root canal and elimination of difficulties, increased blade flexibility and more fracture resistance for higher overall security. Moreover, it owns cross-section varies along the blade for improving the centering ability in the root canal apical third and removal of debris reaching middle and coronal parts ${ }^{(13)}$. A more recently, $\mathrm{AF}^{\mathrm{TM}}$ Blue S ONE File System (Fanta, USA) was introduced; it is manufactured from specially heat treated wire $\mathrm{AF}$ wire $\left(\mathrm{AF}^{\mathrm{TM}}-\mathrm{H}\right)$. According to the manufacturer, it has excellent mechanical strength properties, greater resistance to cyclic fatigue, and its flexibility is enough to avoid canal transportation. Meanwhile, its hardness is large enough to allow for good cutting efficacy. Flawless surface finishing, minimum radial contact to ensure better cutting, variable cross-section on file, increase the volume for upward debris eliminations, together with the variable pitch enables efficient debris transport and reduces the screwing effect ${ }^{(14)}$. Up to our knowledge, there are no studies investigated the surface physical and chemical changes that occur on studied instruments surface after their repeated use. Therefore, this study designed to evaluate surface characteristics and chemical composition changes of NiTi alloy of these instruments before and after three times use.

\section{MATERIALS AND METHODS}

Thirty brand-new endodontic files have tip size $25 / 0.6$ of the following systems were used in this study: Neolix (Neolix, Châtres-la-Forêt, France), One Curve (Micro mega, France) and $\mathrm{AF}^{\mathrm{TM}}$ Blue S ONE One-File System (Fanta, USA). Ninety simulated canals (Endo Training Block-L; Dentsply Maillefer, Ballaigues, Switzerland) with curvature of $45^{\circ} \pm 10^{\circ}$, a taper of 0.02 , an apical diameter of $0.15 \mathrm{~mm}$, and length of $16 \mathrm{~mm}$ were used in this study. Files were equally divided into three groups $(n=10)$ according to type of the file system as follow; Group 1- Neolix, Group 2- One Curve and Group 3$\mathrm{AF}^{\mathrm{TM}}$ Blue S ONE. In order not to interfere in the results of the experiment; files were handled from their packaging carefully using clinical tweezers, were held by their shank; no pre-use instruments cleaning was performed, as they were sterile.

\section{Pre-instrumentation files surface's analysis}

Files were fixed at the shank using utility wax on the SEM holder for been initially analyzed of their topography by Environmental Scanning Electron Microscope ESEM (FEI Quanta 250 FEG, Berlin, Germany) at 500X magnification. using one point in instrument shank (groove detail facing up) as a reference for image reading of the cutting blade (active part) of each file, and the second set of images with the groove detail facing downwards so that the active portion of the file could be seen on both sides. After visualization of each file, the images of the cutting blade (active part) were processed and analysis of the instruments active part micrographs including; the tip, $2 \mathrm{~mm}$ and $4 \mathrm{~mm}$ short of the cutting tip, at 500X magnification. The Ni\& Ti average (wt \%) content on the instruments surface before their use was also analyzed, by using an energy dispersive spectrometer (EDS) (EDAX - AMETEK, Inc., Mahwah, NJ, USA). One EDX spectrum was collected at the tip of each file, as it represents most deformations after use ${ }^{(15)}$ under the following situation: $25 \mathrm{kV}$ accelerating voltage, $110 \mu \mathrm{A}$ beam current, $10^{-6}$ Torr pressure (high-vacuum), analysis area of $130 \times 130 \mu \mathrm{m}$ at magnification 1000 , acquisition time $200 \mathrm{~s}$ and detector dead time $30-35 \%$. Nonstandard analysis mode used to perform the quantitative analysis, utilizing ZAF correction methods, by Genesis software (version 5.2; EDAX) ${ }^{(16)}$. After SEM micrographs taking and EDS readings, the instruments were stored in polypropylene closed numbered tubes.

\section{Simulated Root Canal Preparation}

Working length of the simulated canals was determined using a K-type file size 10 (Dentsply/ Maillefer) that inserted into the simulated canal, until visualized its tip at the canal end. Then, it was 
withdrawn to $1 \mathrm{~mm}$ shorter than obtained length, determining $15 \mathrm{~mm}$ working length. investigated instruments were mounted in a contra-angle has 6:1 gear reduction (Dentsply/Maillefer), powered by an electric motor (Motor X-Smart Plus, Dentsply/ Maillefer), at the setting previously identified for each used system as follow; Group 1- simulated canals were prepared using Neolix files powered with speed of $300 \mathrm{rpm}$ and torque of $1.5 \mathrm{~N} /$ $\mathrm{cm}$, according to manufacturer's instructions in circumferential brushing action until reached the working length. In Group 2 simulated canals were prepared using One Curve files at speed of 300 $\mathrm{rpm}, 2.5 \mathrm{~N} / \mathrm{cm}$ torque according to manufacturer's instructions using direct downward movement in three waves till reaching the working length. Group 3 simulated canals were prepared using $\mathrm{AF}^{\mathrm{TM}}$ Blue $\mathrm{S}$ ONE files powered by the electric torque control motor at speed $350 \mathrm{rpm}$, Torque $2.6 \mathrm{~N} / \mathrm{cm}$ using a gentle inward motion down to the working length. Single operator, a specialist in endodontics prepared all root canals in all groups. After each three pecks, the files were removed for cleaning its flutes gently with sterile gauze, and for canal irrigation using $2 \mathrm{~mL} / 2.5 \% \mathrm{NaOCl}$ solution utilizing a 27-gauge irrigation needle (Dentsply Maillefer, Shanghai, China). Each file was used in three canals preparation, after each canal instrumentation, the files were submitted to thermo-chemical cleaning in an ultrasonic bath (Cristófoli, Campo Mourão, $\mathrm{PR}$, Brazil) using a heating system/ $10 \mathrm{~min}$ at $65^{\circ} \mathrm{C}$ with water/enzymatic detergent Endozime (DFL) at a ratio of $5 \mathrm{~mL} / \mathrm{liter}$ of distilled water.

\section{Post-instrumentation files surface's analysis}

Following first and third instrumentation; the instrument properly dried and stored in polypropylene numbered, closed tubes and sent to SEM equipment for post-instrumentation files surface's topography analysis and NiTi content (wt $\%)$ chemical analysis using EDS on the instruments surface according to the previously described preinstrumentation analysis protocol.

\section{Analysis of SEM micrographs}

All ESEM micrographs of different intervals (pre-instrumentation, after first use, and after third use) were saved on a CD-ROM and applied into PowerPoint program, numbered, and then were projected for three blinded specialized examiners' observation. These examiners were previously calibrated (0.88 and 0.90 - Kappa test). They delivered a spreadsheet includes the number of the examined instrument, the level of evaluation (tip, $0-2 \mathrm{~mm}$ or $2-4 \mathrm{~mm}$ ) and the instrument side to be examined (detail facing up or down), and the criteria for evaluation of each defects and deformation types namely (irregular edges, grooves, micro-cavities and burrs). Using Troian et al. ${ }^{(17)}$ scoring system that was adopted for topographic changes of the instruments classification as follow: 1 - the instrument long axis examined surface has no defect or deformation; 2 - the instrument long axis examined surface with approximately one to three areas with defects or deformations; 3 - the instrument long axis examined surface with approximately four to five areas with defects or deformations; 4 - the instrument long axis examined surface with over five areas with defects or deformations. Examiners were formerly instructed that if they had any doubt between scores, the higher score should be chosen. Statistical Analysis; obtained data submitted to the normality test (Kolmogorov \& Smirnov test) for analyzing the differences in the mean chemical content of the $\mathrm{Ni}$ and $\mathrm{Ti}$ (wt \%) in the instrument surface and to analyze the differences in mean surface defect values between groups and subgroups, the obtained values were statistically analyzed using 1-way ANOVA and Tukey post-hock test $(\mathrm{p}<0.05)$. While, the Kruskal- Wallis test $(\mathrm{p}<0.05)$ was performed to analyze the differences between the mean scores of total surface topographic changes in the instruments surfaces. SPSS program for windows (version.20) used to perform statistical tests. 


\section{RESULTS}

\section{Analysis of Instruments Surface`s Defects (SEM)}

Statistical analysis of recorded surface defects in all examined instruments (Neolix, One Curve and $\boldsymbol{A F}^{\mathbf{T M}}$ Blue $\boldsymbol{S} \boldsymbol{O N E}$ ) revealed occurrence of defects (IE: Irregular Edges, B: Burrs, LG: Longitudinal Grooves and MC: Micro-Cavities) before and after reuse. Regarding each instrument there was nonsignificant difference of each examined defect at each examined level individually (Tip, $0-2 \mathrm{~mm}$, and $2-4 \mathrm{~mm}$ )in all examination interval (before, $1^{\text {st }}$ and, $3^{\text {rd }}$ use). The incidence of defects and deformations observed on the instruments surface before and after the first and third use is in Table 1. Representative SEM micrographs of the examined levels of the instruments (Tip, 0-2mm, and 2-4mm) are in Figure 1.
Statistical analysis of differences between the mean defects values of the examined levels (tip, 0-2 and 2-4) in each file (NEO, OC, AF) individually at each examination interval showed that; in the Neolix files; MC mean values were the highest among all the recorded defects. Significant differences were recorded between Tip and $0-2 \mathrm{~mm}$ levels before use also, between tip and $2-4 \mathrm{~mm}$ after $1^{\text {st }}$ use. The 2-4mm level was significantly lower than 0-2 and tip levels after $3^{\text {rd }}$ use examination interval. On the other hand, the LG mean values showed nonsignificant difference between all examination levels at different examination intervals. The IE mean values showed that the 2-4 level was significantly lower than the Tip and $0-2$ levels at $1^{\text {st }}$ and $3^{\text {rd }}$ examination interval. While, the $\mathbf{B}$ recorded lowest defect mean values, with significant difference between all examination levels before and after $1^{\text {st }}$ use examination intervals only. The One Curve

TABLE (1) Comparison between study groups according to Mean \pm SD of defects up to $4 \mathrm{~mm}$ of their active part; before, after 1st and 3rd use.

\begin{tabular}{|c|c|c|c|c|c|c|c|c|c|c|c|}
\hline \multirow[t]{2}{*}{ Defect } & \multirow{2}{*}{$\begin{array}{l}\text { File } \\
\text { level }\end{array}$} & \multicolumn{3}{|c|}{ G.1: Neolix (n=10) } & \multicolumn{3}{|c|}{ G.2: One Curve(n=10) } & \multicolumn{3}{|c|}{ G.3: AF-Blue (n=10) } & \multirow{2}{*}{$\begin{array}{c}p \\
\text { value }\end{array}$} \\
\hline & & Before & $1^{\text {st }}$ & $3^{\text {rd }}$ & Before & $1^{\text {st }}$ & $3^{\text {rd }}$ & Before & $1^{\mathrm{st}}$ & $3^{\text {rd }}$ & \\
\hline \multirow{3}{*}{ IE } & Tip & $5.33^{\mathrm{A}} \pm 0.58$ & $5.67^{\mathrm{Ax}} \pm 0.58$ & $5.67^{\mathrm{Ax}} \pm 0.58$ & $0 \pm 0^{\mathrm{B}}$ & $0 \pm 0^{\mathrm{B}}$ & $0^{\mathrm{B}}$ & $3.67^{\mathrm{A}} \pm 0.58$ & $3.67^{\mathrm{AX}} \pm 0.58$ & $3.67^{\mathrm{AX}} \pm 0.58$ & $\leq 0.05$ \\
\hline & $0-2$ & $3.33^{\mathrm{A}} \pm 0.58$ & $4.33^{\mathrm{AX}} \pm 0.58$ & $4.33^{\mathrm{AX}} \pm 0.58$ & $0 \pm 0^{\mathrm{B}}$ & $0.33^{\mathrm{B}} \pm 0.58$ & $00.33^{\mathrm{B}} \pm 0.58$ & $1.33^{\mathrm{B}} \pm 1.53$ & $1.33^{\mathrm{BY}} \pm 1.53$ & $1.67^{\mathrm{BXY}} \pm 2.08$ & $\leq 0.05$ \\
\hline & $2-4$ & $1.33^{\mathrm{A}} \pm 0.58$ & $1.67^{\mathrm{AY}} \pm 1.15$ & $2.33^{\mathrm{AY}} \pm 0.58$ & $0 \pm 0^{\mathrm{A}}$ & $0 \pm 0^{\mathrm{A}}$ & $0 \pm 0^{\mathrm{B}}$ & $0 \pm 0^{\mathrm{A}}$ & $0 \pm 0^{A Y}$ & $0 \pm 0^{\mathrm{BY}}$ & $\leq 0.05$ \\
\hline p- value & & NS & $\leq 0.05$ & $\leq 0.05$ & NS & NS & NS & NS & $\leq 0.05$ & $\leq 0.05$ & \\
\hline \multirow{3}{*}{ B } & Tip & $4.67^{\mathrm{AX}} \pm 0.58$ & $5.00^{\mathrm{XA}} \pm 0.00$ & $5.00^{\mathrm{A}} \pm 0.00$ & $0 \pm 0^{\mathrm{B}}$ & $0 \pm 0^{\mathrm{B}}$ & $0 \pm 0^{\mathrm{B}}$ & $0.68^{\mathrm{B}} \pm 0.58$ & $0.67^{\mathrm{B}} \pm 0.58$ & $0.67^{\mathrm{B}} \pm 0.58$ & $\leq 0.05$ \\
\hline & $0-2$ & $2.33^{\mathrm{AY}} \pm 0.58$ & $2.67^{\mathrm{YA}} \pm 0.58$ & $3.00^{\mathrm{A}} \pm 0.00$ & $0 \pm 0^{\mathrm{B}}$ & $0.33^{\mathrm{B}} \pm 0.58$ & $0.33^{\mathrm{B}} \pm 0.58$ & $0 \pm 0^{\mathrm{B}}$ & $0 \pm 0^{\mathrm{B}}$ & $0 \pm 0^{\mathrm{B}}$ & $\leq 0.05$ \\
\hline & $2-4$ & $0.33^{\mathrm{AZ}} \pm 0.58$ & $0.67^{\mathrm{ZA}} \pm 0.58$ & $0.67^{\mathrm{A}} \pm 0.58$ & $0 \pm 0^{\mathrm{A}}$ & $0 \pm 0^{\mathrm{A}}$ & $0 \pm 0^{\mathrm{A}}$ & $0 \pm 0^{\mathrm{A}}$ & $0 \pm 0^{\mathrm{A}}$ & $0 \pm 0^{\mathrm{A}}$ & NS \\
\hline $\mathrm{p}$ - value & & $\leq 0.05$ & $\leq 0.05$ & NS & NS & NS & NS & NS & NS & NS & \\
\hline \multirow{3}{*}{ LG } & Tip & $7.00^{\AA} \pm 0.00$ & $8.00^{\mathrm{A}} \pm 1.00$ & $8.67^{\mathrm{A}} \pm 1.53$ & $4.00^{\mathrm{BC}} \pm 1.00$ & $4.667^{\mathrm{BC}} \pm 1.16$ & $5.00^{\mathrm{BC}} \pm 1.00$ & $6.00^{A C} X_{ \pm 1.00}$ & $6.67^{\mathrm{ACX}} \pm 0.58$ & $7.00^{A C} \pm 1.00$ & $\leq 0.05$ \\
\hline & $0-2$ & $6.67^{\mathrm{A}} \pm 0.58$ & $6.67^{\mathrm{A}} \pm 1.16$ & $7.00^{\mathrm{A}} \pm 0.00$ & $2.67^{\mathrm{B}} \pm 0.58$ & $3.00^{\mathrm{BC}} \pm 0.00$ & $3.00^{\mathrm{B}} \pm 0.00$ & $5.00^{\mathrm{AX}} \pm 1.00$ & $5.67^{\mathrm{ACXZ}} \pm 1.16$ & $6.00^{\mathrm{A}} \pm 1.00$ & $\leq 0.05$ \\
\hline & $2-4$ & $6.33^{\mathrm{A}} \pm 0.58$ & $6.67^{\mathrm{A}} \pm 0.58$ & $7.00^{\mathrm{A}} \pm 0.00$ & $2.00^{\mathrm{B}} \pm 1.00$ & $2.667^{\mathrm{B}} \pm 1.53$ & $2.67^{\mathrm{B}} \pm 1.53$ & $3.00^{\mathrm{BY}} \pm 1.00$ & $3.33^{\mathrm{BYZ}_{ \pm}} 0.58$ & $3.33^{\mathrm{B}} \pm 0.58$ & $\leq 0.05$ \\
\hline $\mathrm{p}$ - value & & NS & NS & NS & NS & NS & NS & $\leq 0.05$ & $\leq 0.05$ & NS & \\
\hline \multirow{3}{*}{ MC } & Tip & $11.00^{\mathrm{XA}} \pm 0.0$ & $13.33^{\mathrm{XA}} \pm 1.53$ & $13.67^{\mathrm{XA}} \pm 1.16$ & $8.00^{\mathrm{BCX}} \pm 1.0$ & $8.33^{\mathrm{BC}} \pm 0.58$ & $9.00^{\mathrm{B}} \pm 1.0$ & $9.67^{\mathrm{AC}_{ \pm}} \pm 0.58$ & $10.33^{A C} \pm 0.58$ & $10.66^{\mathrm{B}} \pm 0.58$ & $\leq 0.05$ \\
\hline & $0-2$ & $8.67^{\mathrm{YZA}} \pm 0.58$ & $10.3^{\mathrm{XZA}} \pm 0.58$ & $10.7^{\mathrm{XZA}} \pm 1.53$ & $5.33^{\mathrm{BY}} \pm 1.16$ & $6.33^{\mathrm{B}} \pm 1.16$ & $6.33^{\mathrm{B}} \pm 1.16$ & $9.67^{\mathrm{A}} \pm 0.58$ & $11.00^{\mathrm{A}} \pm .1 .00$ & $11.33^{\mathrm{A}} \pm 0.58$ & $\leq 0.05$ \\
\hline & $2-4$ & $9.00^{\mathrm{XZA}} \pm 1.00$ & $10.0^{\mathrm{YZA}} \pm 1.00$ & $10.00^{\mathrm{YA}} \pm 1.00$ & $5.00^{\mathrm{BY}} \pm 1.53$ & $5.333^{\mathrm{B}} \pm 1.53$ & $6.33^{\mathrm{BC}} \pm 1.53$ & $7.67^{\mathrm{A}} \pm 0.58$ & $8.667^{\mathrm{A}} \pm 1.16$ & $8.67^{\mathrm{AC}} \pm 1.16$ & $\leq 0.05$ \\
\hline p- value & & $\leq 0.05$ & $\leq 0.05$ & $\leq 0.05$ & $\leq 0.05$ & NS & NS & NS & NS & NS & \\
\hline \multicolumn{2}{|c|}{ p-value } & \multicolumn{9}{|c|}{0.001} & \\
\hline
\end{tabular}

Mean values have same superscript capital letters $(X, Y$ and $Z)$ means non-significant difference between compared items within the same column. 
files analysis showed that; MC mean defect values were the highest among recorded defects, with significant difference only between Tip and 0-2, Tip and 2-4 examined levels before use. On the other hand, other recorded defects ( LG, IE, and B) mean values showed non-significant.

\section{Regarding the $\mathrm{AF}^{\mathrm{TM}}$ Blue S ONE files; the MC,}

B defects recorded the highest and lowest mean values respectively among recorded defects, with non-significant difference between all examined levels at all examination intervals. While the IE mean defect values showed significant difference only between Tip/0-2 and Tip /2-4 examination levels after $1^{\text {st }}$ use examination interval, and between tip/ 2-4 at $3^{\text {rd }}$ use interval. Also, the $\mathbf{L G}$ mean defect values at 2-4 level were significantly lower than the tip at $1^{\text {st }}$ use interval.

The comparison between the tested files (Intergroups) at each level and interval (use) revealed that;

Neolix files and One Curve files showed the

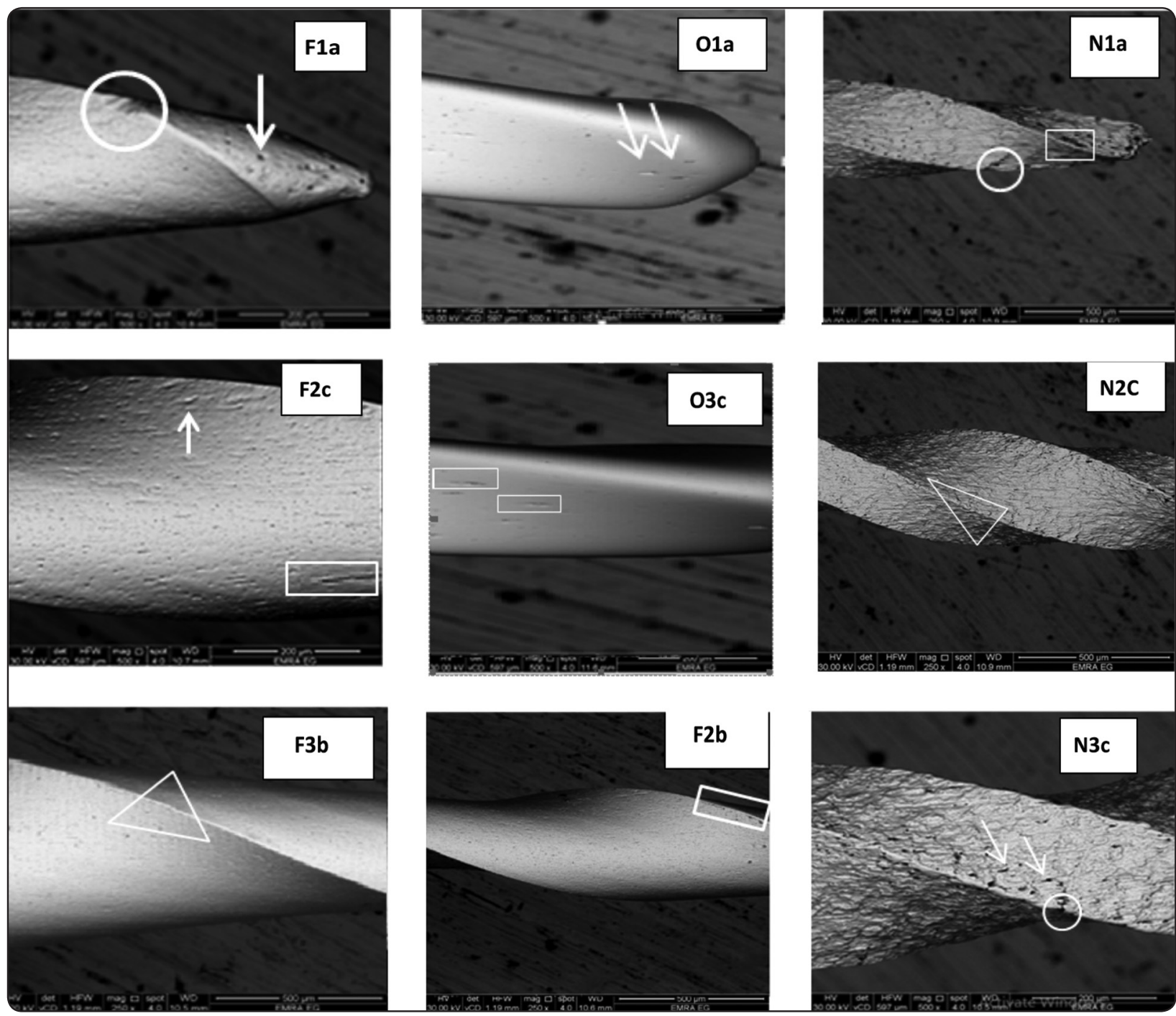

Fig. (1) Representative SEM micrographs of the instruments surface before, after 1st and 2nd uses. Magnification $\times 500$, (arrow) Micro-cavities, (circle) Irregular Edges, (triangle) Burrs, and (box) Longitudinal Grooves. Numbers denotes examination intervals (1; before,2; 1 st and3; 3rd uses). Capital letters (F; AF file, O; One Curve and N; Neolix file). Small letters denotes examination levels (a; Tip, b; 0-2mm and c; 2-4mm). 
highest and lowest mean surface defect values respectively at all level and intervals. The Neolix files recorded significant higher mean surface defect values of LG, MC, IE, and B than One Curve files at all levels and intervals except at 2-4 level that showed no significant differences at before and $1^{\text {st }}$ use for IE defect and at before, $1^{\text {st }}$ and $3^{\text {rd }}$ use for B defect . Moreover, Neolix files showed higher significant mean defect values than $\boldsymbol{A F}^{\mathbf{T M}}$ Blue $\boldsymbol{S}$ ONE files regarding IE (in 0-2 level at all intervals, 2-4 level at $3^{\text {rd }}$ use), B ( in Tip and 0-2 level at all intervals), and LG (in 2-4 level at all intervals). On the other hand, the One Curve files showed significantly lower mean surface defect values than $\boldsymbol{A F}^{\mathbf{T M}}$ Blue $\boldsymbol{S}$ ONE file regarding the IE at file's Tip at all examination intervals, $\mathbf{M C}$ at $0-2 \mathrm{~mm}$, in all examination intervals, and $\mathbf{L G}$ at $0-2 \mathrm{~mm}$ before and after $3^{\text {rd }}$ uses.

The analysis of median score values for total surface defects revealed that; No significant differences were found between different intervals of use (pre,1st and 3rd uses) and levels within each tested file. Neolix files showed the highest statistically significant median score values at all levels and intervals.

Quantitative Analysis of Ni and Ti (EDS): The mean values (wt \%) of $\mathrm{Ni}$ and $\mathrm{Ti}$ content on the instruments surface are in Figures 2. All examined file systems Neolix file, One Curve and $\mathrm{AF}^{\mathrm{TM}}$ Blue $\mathrm{S}$ ONE file had significant decrease in Ni content between all examination intervals (before use, after $1^{\text {st }}$ and $3^{\text {rd }}$ uses) $\mathrm{p}<0.05$. Regarding Ti content, Neolix file and One Curve files the instruments had no significant decrease throughout use $(\mathrm{p}>0.05)$. However, $\mathrm{AF}^{\mathrm{TM}}$ Blue $\mathrm{S}$ ONE file, showed a significant decrease of $\mathrm{Ti}$ content between $3^{\text {rd }}$ use interval with before and after $1^{\text {st }}$ use values $(p>0.05)$.

Inter-groups correlation revealed; nonsignificant difference in $\mathrm{Ni} \%$ values between all files at examination intervals were noticed except, significant difference between One Curve and $\mathrm{AF}^{\mathrm{TM}}$

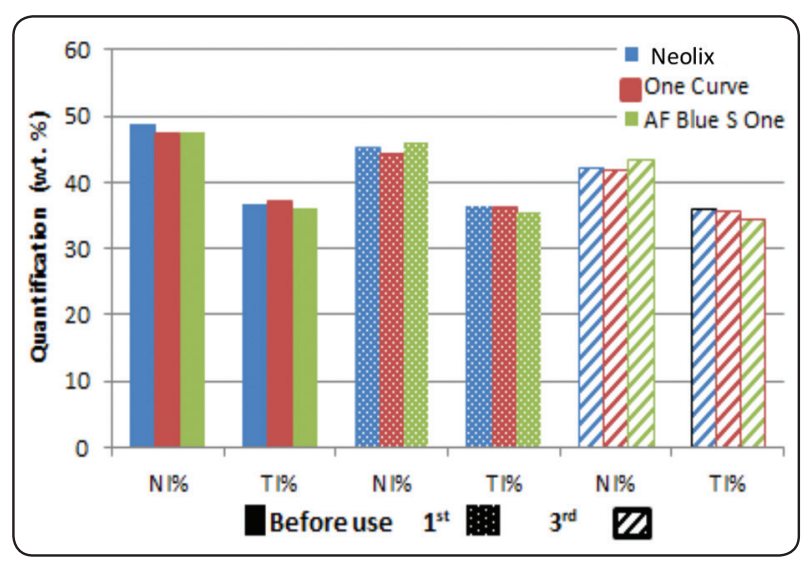

Fig. 2: Mean values of Ni and Ti quantification before and after 1 st and 3 rd instruments use.

Blue S ONE files after $3^{\text {rd }}$ used. No significant difference in $\mathrm{Ti} \%$ values between Neolix file, One Curve and $\mathrm{AF}^{\mathrm{TM}}$ Blue $\mathrm{S}$ ONE file before use. However, AF ${ }^{\mathrm{TM}}$ Blue S ONE files showed significant lower Ti \% than Neolix and One curve files at $1 \mathrm{st}$ and 3rd uses.

\section{DISCUSSION}

Natural dentition retained functioning and esthetically accepted is the basic goal of endodontic treatment. Accomplishment of such goal relies on variety of steps starting from proper selection of the case and treatment plan up-to final restoration. Schilder (18) established clinical objectives of cleaning and shaping including development of a continuously tapered canal with maintaining its original shape and curvature. Instruments made from nickel-titanium alloy development considered as the leap in achieving such objectives owing to their super-elasticity and shape memory ${ }^{(1)}$. Despite of this; their sudden fracture is a clinical concern "nightmare" that has varied incidence from $3 \%$ to $21 \%(4,19)$. Therefore, awareness about the leading factors to instrument fracture is important which occurs even there is no visibly detected sign of defects, it shouldn't be ignored that operator's proficiency as well as root canal morphology were recorded to have influential role on the fracture incidence $^{(20,21)}$. On the other hand; improvement of 
$\mathrm{Ni} \mathrm{Ti}$ instrument's flexibility and fatigue fracture became main concern for manufacturers through including different manufacturing process, thermomechanical treatments of the alloy and modifications in cross-sectional design ${ }^{(1,22,23)}$. So, manufacturers switch to single use Ni-Ti rotary files as a favorable step for instrument failure prevention due to repeated use ${ }^{(24-26)}$. But, even brand-new instruments are not fortified against failure ${ }^{(27)}$. Instruments included in this study are recommended for single use according to their manufacturers. However, in our work we use them for three times per each file. As the cumulative influence of multiple clinical uses on instrument's surface physical and chemical characteristics provides direct hint about their fatigue failure behavior and the unexpected fracture risk too ${ }^{(3,28)}$. For group's standardization, tested files had same tip size and taper $25 / 6 \%$. Also, simulated used canals had the same curvature of $45^{\circ} \pm 10^{\circ}$, 0.02 taper, 0.15 apical diameter $\mathrm{mm}$ and $16 \mathrm{~mm}$ length. Unfortunately, resin blocks don't mimic the clinical situation due to circular cross section that influenced torsional loads on the instruments ${ }^{(29)}$. On contrary; Schafer \&Florek ${ }^{(30)}$ recorded higher values of torsional loads for resin (simulated canals) during instrumentation than of dentine (natural canals), which might mean that the failure resistance in natural canals is probably even greater than produced in the resin of the simulated canal. In this study, file`s surface topography analysis performed using SEM which proved as an accurate tool for evaluating the morphological changes of metallic materials, as endodontic instruments repeatedly, without affecting their physical properties (31,32). Rotary NiTi instruments evaluated in this research showed variable surfaces defects although they were brand new, which could be inferred to the process of instruments manufacturing. This is in accordance with Chianello et al. ${ }^{(33)}$ who proved no topographic irregularities free NiTi instrument, and at least 2 to 7 defects were recorded on the surface even before use. In this study pre-instrumentation images showed; Neoniti file had significantly higher percentage of surface defects than other tested file systems (One Curve and $\mathrm{AF}^{\mathrm{TM}}$ Blue S ONE) which may be attributed to its manufacturing technique utilizing a recently developed process; wire-cut electrical discharge machining (WEDM) that gives a rough surface, leads to abrasive properties that aim to enhance the speed of root canal preparation ${ }^{(11,12)}$. On the other hand; One Curve file group showed the least pre-instrumentation defects which may inferred to its manufacturing technique, as manufacturer's claims it's made of heat treated Ni Ti wire (C. Wire) with a technique designed, developed and applied exclusively by MICRO-MEGA. The results showed that surface defects increased after $1^{\text {st }}$ use and after $3^{\text {rd }}$ use in accordance with other studies that confirmed surface defects existence on endodontic file before use, may procure more surface damage after use ${ }^{(8,34)}$. Neoniti file group recorded the highest increase in surface defects after use; this could be related to its non-homogeneous rectangular cross section. While the One curve file has variable crosssection triple-helical to $\mathrm{S}$ shape and AF Blue $\mathrm{S}$ ONE has variable cross-section on file triangular to $\mathrm{S}$ shape. These findings were explained in previous studies stating that; instruments with rectangular or square cross-sectional design has less flexibility, less stress distribution of along its length and highest stress concentrations in comparison with a triangular and S-shaped cross-section being more vulnerable to plastic deformations ${ }^{(35.36)}$. On the other hand, it couldn't be ignored that non homogenous surface of NiTi instruments and their softer cutting edges than the core of instruments lead to a lower cutting efficiency, a higher wear and a higher frequency of exchange of files ${ }^{(37)}$. In this study; all tested groups recorded the highest pre-instrumentation manufacturing defect at file's tip which came against the manufacturers claims that the tips of rotary instruments should be conic, smooth. This in accordance with Sattapan et $\boldsymbol{a l}{ }^{(15)}$ who stated that as the file taper increased, more bulk is given than its tip which accounts for files fracture close to the tip clinically due to less 
strength. The surface of NiTi alloy files proved to be formed of titanium oxide ( $\mathrm{TiO} 2)$, less nickel oxide $(\mathrm{NiO})$ quantities and metallic nickel (Ni2O3) (38) , this layer has an important role in preventing wear and corrosion of the alloy internal layer ${ }^{(38,22)}$. This unique chemical composition and geometry formed via a strong binary intermetallic bond (20 to $200 \mathrm{Kcal} / \mathrm{mol}$ ) and bonding force (equiatomic) between Ni \& Ti atoms of NiTi alloys, proved to be changed by; thermodynamic process, submission to stresses during root canal preparation ${ }^{(27)}$. On the other hand; Kalyoncuo.lu Despite et al. ${ }^{(39)}$ reported non-significant change of Ni \& Ti content before and after instruments use which against results of this study where both $\mathrm{Ni}$ and $\mathrm{Ti}$ atoms recorded decrease after use, but the decrease in Ni content was significantly higher than $\mathrm{Ti}$ that comes in accordance with Otsuka \& Ren ${ }^{(38)}$. In this study; Micro-cavities were the highest recorded defect in all examined file systems in all evaluation intervals which might be attributed to loss of $\mathrm{Ni}$ and $\mathrm{Ti}$ atoms showed by EDS analysis on instruments surface after reuse, that comes in accordance with; Bastos et al ${ }^{(40)}$, Otsuka \& Ren ${ }^{(38)}$ Who proved that by repeated instrument use deteriorates the surface oxide layer, compromise the NiTi alloy to corrosion, that deteriorates the intermetallic bond, and allow easier Ni electron loss by oxidation than Ti electrons. None of the investigated instruments presented fracture that might be attributed to performance of preparation by single operator "endodontics specialist" that seems to influence the failure resistance of the files Generali et al ${ }^{(41)}$. On the other hand; this may be related to advances in manufacturing techniques as follow; Neoniti subjected to proper heat treatment that leads to increase in flexibility and shape memory of this system, One Curve made of heat-treated NickelTitanium alloy (C. Wire) which is exclusively developed and implemented for controlled memory of NiTi and capacity to pre-bend, and $\mathrm{AF}^{\mathrm{TM}}$ Blue $\mathrm{S}$ ONE, is manufactured from specially heat treated wire $\mathrm{AF}$ wire $\left(\mathrm{AF}^{\mathrm{TM}}-\mathrm{H}\right)$, that has excellent mechanical strength properties, greater resistance to cyclic fatigue, and good cutting efficacy ${ }^{(14)}$. These results denote that rotary endodontic files manufacturing and packaging process are far from targeted. Therefore, manufacturers should develop refinements in the machining techniques, to diminish the surface defects and thereby increase the clinical performance.

\section{CONCLUSION}

Within the limitations of this study, no brand new instrument were free of surface defects, these defects increase after instruments put in use and after multiple use. Ni \& Ti contents of instruments surface decreased after instruments use which negatively affects prevalence of surface defects.

\section{REFERENCES}

1. Schafer E, Erler M, Dammaschke T. Comparative study on the shaping ability and cleaning efficiency of rotary Mtwo instruments. Part 2. Cleaning effectiveness and shaping ability in severely curved root canals of extracted teeth. Int Endod J. 2006;39:203-12.

2. Walia HM, Brantley WA, Gerstein H. An initial investigation of the bending and torsional properties of Nitinol root canal files. J Endod. 1988;14:346-51.

3. Hanan AR, Meireles DA, Sponchiado Júnior EC, Hanan S, Kuga MC, Bonetti Filho I. Surface characteristics of reciprocating instruments before and after use--a SEM analysis. Braz Dent J 2015;26:121-7.

4. Sattapan B, Nervo GJ, Palamara JE, Messer HH. Defects in rotary nickel-titanium files after clinical use. J Endod. 2000;26(3):161-5.

5. Versluis A, Kim HC, Lee W, Kim BM, Lee CJ. Flexural stiffness and stresses in nickel-titanium rotary files for various pitch and cross-sectional geometries. J Endod. 2012;38:1399-403.

6. Martins RC, Bahia MG, Buono VT. Surface analysis of ProFile instruments by scanning electron microscopy and X-ray energy-dispersive spectroscopy: a preliminary study. Int Endod J. 2002;35:848- 53.

7. Parashos P, Messer HH. Rotary NiTi instrument fracture and its consequences. J Endod. 2006;32(11):1031-43 
8. Alapati SB, Brantley WA, Iijima M, Clark WA, Kovarik L, Buie C, Liu J, Ben Johnson W. Metallurgical characterization of a new nickel titanium wire for rotary endodontic instruments. J Endod. 2009;35(11):1589-93.

9. Burklein S, Hinschitza K, Dammaschke T, Schafer E. Shaping ability and cleaning effectiveness of two singlefile systems in severely curved root canals of extracted teeth: Reciproc and WaveOne versus Mtwo and ProTaper. Int Endod J. 2012;45(5):449-61.

10. Moghadam KN, Shahab S, Rostami G. Canal transportation and centering ability of twisted file and reciproc: a conebeam computed tomography assessment. Iran Endod J. 2014;9(3):174.

11. Dhingra A, Gupta R, Yadav V, Aggarwal N. Endodontic retreatment using single file Neolix system. American $\mathrm{J}$ Oral Mede and Radiol. 2015;2(4):206-8.

12. Gergi R, Sabbagh C. Effectiveness of two nickel-titanium rotary instruments and a hand file for removing guttapercha in severely curved root canals during retreatment: an ex vivo study. Int Endod J 2007;40(7):532-537.

13. Amr M.Elnaghy and Shaymaa E.Elsaka. Cyclic Fatigue Resistance of One Curve, 2Shape, ProFile Vortex, Vortex Blue, and RaCe Nickel-Titanium Rotary Instruments in Single and Double Curvature Canalsl. J Endod. 2018; 44(11) :1725-30

14. Shanghai Fanta Dental Materials CO.,Ltd (http://www. fanta-dental.com/)

15. Sattapan B, Joseph E.A. Palamara and Harold h. Messer, Torque During canal instrumentation using rotary Nickel Titanium files J Endod-2000; 3 (26):156-60.

16. Zinelis $\mathrm{S}$, Eliades $\mathrm{T}$,Eliades G.A. metallurgical characterization of ten endodonticNi-instruments: assessing the clinical relevanceof shape memory and superelastic properties ofNi-Ti endodontic instruments. Int Endod J.2010;43, 125-34.

17. Troian CH, Só MVR, Figueiredo JAP, Oliveira EPM. Deformation and fracture of $\mathrm{RaCe}$ and $\mathrm{K} 3$ endodontic instruments according to the number of uses. Int Endod J 2006;39:616-25.

18. Schilder, H. (1974) Cleaning and shaping the root canal. Dent Clin of North Am, 18, 269-296.

19. Shen Y, Cheung GS, Bian Z, et al. Comparison of defects in ProFile and ProTaper systems after clinical use. J Endod 2006;32:61-5.
20. Parashos P, Gordon I, Messer HH. Factors influencing defects of rotary nickel-titanium endodontic instruments after clinical use. J Endod 2004;30:722-5.

21. Shen Y, Haapasalo M, Cheung GS, et al. Defects in nickeltitanium instruments after clinical use. Part 1: Relationship between observed imperfections and factors leading to such defects in a cohort study. J Endod 2009;35:129-32.

22. Gambarini G,Plotino G, Grande NM,Al-Sudani D, De Luca M, Testarelli L. Mechanicalproperties of nickel-titanium rotary instruments produced with a new manufacturing technique. Int Endod J. 2011 Apr;44(4):337-41.

23. Shen Y, Qian W, Abtin H, Gao Y, Haapasalo M. Fatigue testing of controlled memory wire nickel-titanium rotary instruments. J Endod. 2011 Jul;37(7):997-1001.

24. Plotino G, Grande NM, Sorci E, et al. A comparison of cyclic fatigue between used and new Mtwo Ni-Ti rotary instruments. Int Endod J 2006;39:716-23.

25. Vieira EP, Franca EC, Martins RC, et al. Influence of multiple clinical use on fatigue resistance of ProTaper rotary nickel-titanium instruments. Int Endod J 2008;41:163-72.

26. Galva o Barbosa FO, Ponciano Gomes JA, Pimenta de Arau' jo MC. Influence of previous angular deformation on flexural fatigue resistance of $\mathrm{K} 3$ nickel-titanium rotary instruments. J Endod 2007;33:1477-80.

27. Arens FC, Hoen MM, Steiman HR, et al. Evaluation of single-use rotary nickel-titanium instruments. J Endod 2003;29:664-6.

28. Al-Hadlaq SMS, Al Jarbou FA,Al Thumairy RI. Evaluation of cyclic flexural fatigue of M-Wire nickel-titanium rotary instruments. J Endod 2010;36:305-307.

29. Peters OA, Barbakow F. Dynamic torque and apical forces of Profile.04 rotary instruments during preparation of curved canals. Int Endo J 2002; 35:379-89.

30. Schafer E, Florek H. Efficiency of rotary nickel-titanium K3 instruments compared with stainless steel hand K-Flexofile. Part 1. Shaping ability in simulated curved canals. Int Endo J 2003;36, 199-207.

31. Gavini G, Caldeira CL, Akisue E, Candeiro GTM, Kawakami DAS. Resistance to flexural fatigue of Reciproc R25 files under continuous rotation and reciprocating movement. J Endod 2012;38:684-7.

32. Prati C, Zamparini F, Scialabba VS, Gatto MR, Piattelli A, Montebugnoli L. A 3-year prospective cohort study on 
132 calcium phosphateblasted implants: flap vs flapless technique. Int J Oral Maxillofac Implants 2016;31:413-23.

33. Chianello G, Specian VL, Hardt LC, Raldi DP, LageMarques JL, Habitante SM. Surface finishing of unused rotary endodontic instruments: a SEM study. Braz Dent J 2008;19:109-13.

34. Pirani C, Paolucci A, Ruggeri O, Bossù M, Polimeni A, Gatto MR. Wear and metallographic analysis of WaveOne and Reciproc NiTi instruments before and after three uses in root canals. Scanning 2014;36:517-25.

35. Ha JH, Cheung GS, Versluis A, Lee CJ, Kwak SW, Kim HC, et al. 'Screw-in' tendency of rotary nickel-titanium files due to design geometry. Int Endod J. 2015;48:666-72.

36. Kim HC, Kim HJ, Lee CJ, Kim BM, Park JK, Versluis A, et al. Mechanical response of nickel-titanium instruments with different cross-sectional designs during shaping of simulated curved canals. Int Endod J. 2009;42:593-602 .
37. Schafer E. Wurzelkanalinstrumente fur den manuellen Einsatz. Schneidleistung und Formgebung gekru“ mmter Wurzelkanalabschnitte. Berlin: Quintessenz; 1998.

38. Otsuka K, Ren X. Physical metallurgy of Ti-Ni based shape memory alloys. Prog Mater Sci 2005;50:511-678.

39. Kalyoncuoğlu E, Keskin C, Uzun İ, Bengü AS, Guler B. Scanning electron microscopy with energy dispersive $\mathrm{X}$-ray spectrophotometry analysis of reciprocating and continuous rotary nickel-titanium instruments following root canal retreatment. J Oral Sci 2016;58:401-406.

40. Bastos MM, Hanan AR, Bastos AM, Marques AF, Garcia FR, Sponchiado-Júnior EC.Topographic and Chemical Analysis of Reciprocating and Rotary Instruments Surface after Continuous Use. Braz Dent. (2017) 28(4): 461-466

41. Generali L, Righi E, Todesca MV, Consolo U. Canal shaping with WaveOne reciprocating files: J Odontology influence of operator experience on instrument breakage and canal preparation time.2014;102:217-22. 